\title{
Self-care and its predictive role in the quality of life of the elderly living in the community
}

SangSefidi S ${ }^{1}$, Ghanbari Moghaddam A², Mohamadzadeh $\mathrm{M}^{3}$, Karbalaee Z4, ${ }^{*}$ Mohammadi $\mathrm{M}^{5}$

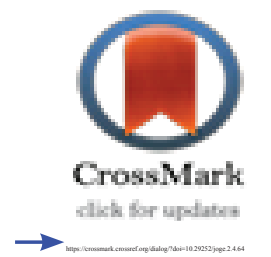

1- Msc of grontology Nursing, Bojnourd University of Medical Sciences, Bojnourd, Iran.

2- Iranian Research Center on Healthy Aging, Sabzevar University of Medical Sciences, Sabzevar, Iran.

3- Msc of Health Education, North Khorasan University of Medical Sciences, North Khorasan, Iran.

4- MSc of Nursing, Faculty of Nursing, University of Social Welfare \& Rehabilitation Sciences, Tehran, Iran.

5- Iranian Research Center on Healthy Aging, Sabzevar University of Medical Sciences, Sabzevar, Iran

(Corresponding Author)

E-mail: mohammadiuswr@gmail.com

\section{Abstract}

Introduction: Quality of life is one of the important issues in today's health care. Despite the high importance of self-care and quality of life in improving the health of the elderly, unfortunately, this issue has not been sufficiently addressed in Iran. The aim of this study was to determine the predictive value of self-care capacity of elderly people in improving their quality of life in Bojnourd in r. $\mathbf{v}$.

Method: This is a descriptive-analytical study that was carried out by sampling $\wedge$. elderly people using a multi-stage cluster sampling method among elderly people living in the city of Bojnourd during the months of August to September. The instruments used in this study were demographic variables, quality of life questionnaire (SF $/ Y$ ), self-care capacity questionnaire for elderly people (SASE). SPSS software version $r$ was used to describe and analyze the data. Descriptive and analytical statistics such as Kolmogorov-Smirnov test, Mann-Whitney U., Spearman correlation coefficient and multivariable regression analysis were used.

Results: The mean age in this study was $99 . \Delta \pm 9$. The average self-care ability score was $90.44 \pm$

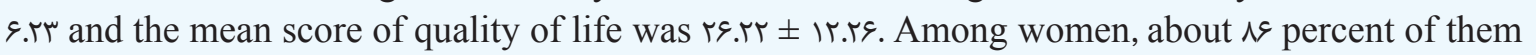
had low self-care. The relationship between self-care capacity and quality of life was week and was not statistically significant $(\mathrm{P}<\cdot . \cdot \Delta)$. Also, the predictive power of self-care power to gain higher scores in quality of life was not statistically significant $(\mathrm{P}<\cdot . \cdot \Delta)$.

Conclusion: Considering the low self-care capacity of most elderly people in Bojnourd city and especially the elderly women of this city, it is recommended that factors affecting self-care capacity be investigated and planned and measures taken to improve the status of self-care capacity by the relevant authorities. Take up Self-care can not predict changes in the quality of life in the elderly.

Key words: Elderly, Self-care ability, Quality of life.

Received: 21 October 2017

\begin{tabular}{|l|l|}
\hline \multicolumn{3}{|c|}{ Access this article online } \\
\hline
\end{tabular}




\section{توان خود مر اقبتى و نقش بيشكَويى كننده آن در كيفيت زندكى سالمندان ساكن جامعه}

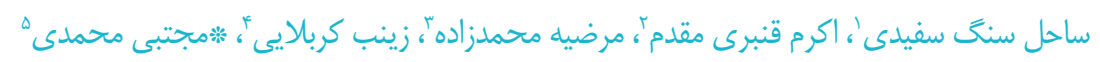

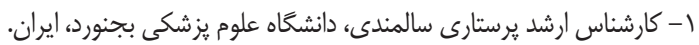

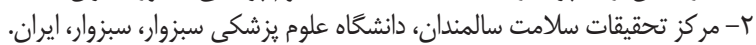

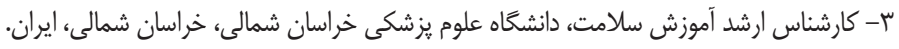

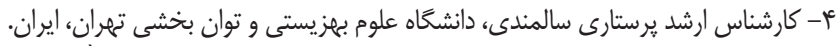

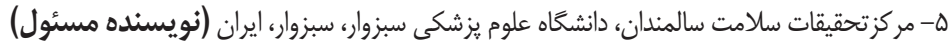
بست الكترونيكى: mohammadiuswr@gmail.com

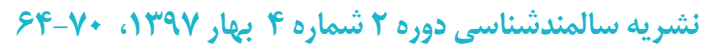

\section{مقدمه: كيفيت زندگى يكى از مسائل مهم عصر امروز در مراقبت سلامتى است. با وجود اهميت بسيار زياد امر خودمراقبتى و كيفيت

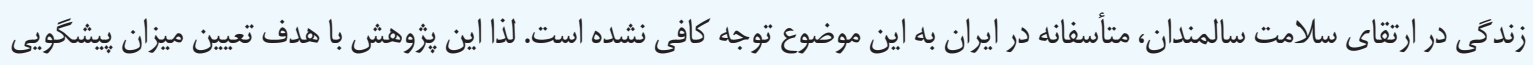

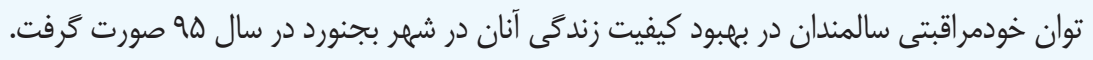

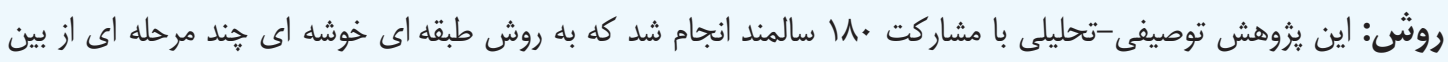

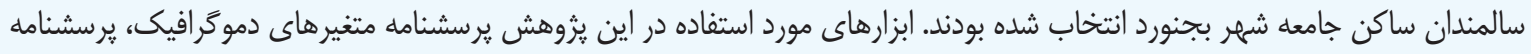

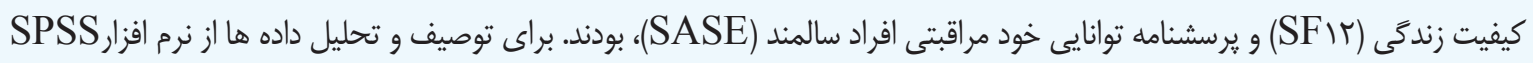
نسخه آ استفاده كرديد.

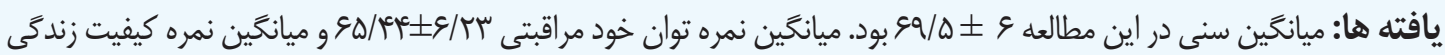

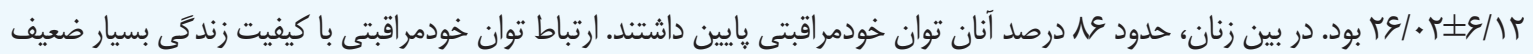

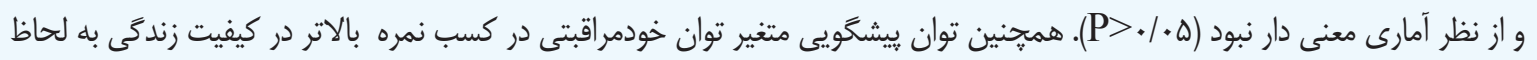

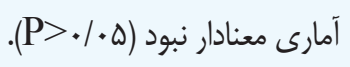

نتيجه كَيرى: همجنين با توجه به توان خود مراقبتى بايين اكثر سالمندان شهر بجنورد و بخصوص زنان سالمند اين شهر، توصيه

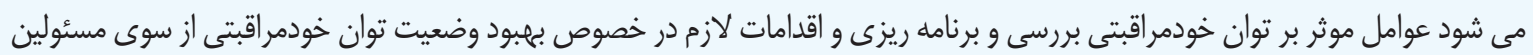

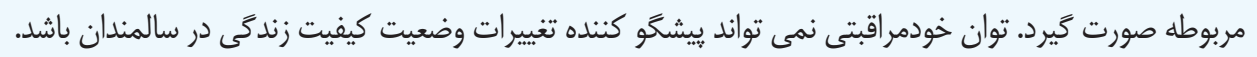

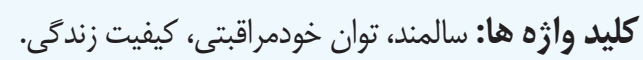

تاريخ بذيرش:

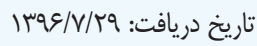


مؤسسات و سر اهاى نكمهدارى را افر اد بالاى هوسال به خود اختصاص مى دهند و به طور كلى •و درصد از هزينه مراقبت هاى يزشكى توسط اين كَروه سنى مصرف مى شود (^).. مطالعات ديخر نشان مى دهند كه حدود + أه بيماران سالمند در دوران بسترى افت سطح

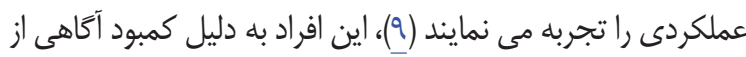

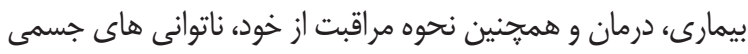

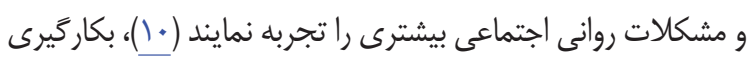

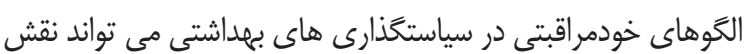

مهمى در افزايش سطح سلامت جامعه داشته باشد (1). با وجود اهميت بسيار زياد امر خودمراقبتى و ارتباط آن با بالبال كيفيت زندگى سالمندان ساكن جامعل، متأسفانه به اندازه كافى به اين موضوع توجه كافى نشده است و على رغم رشد جمعيت سالمندان و تغييرات هرم جمعيتى كشور، هنوز بر نيازهاى سالمندان به عنوان يك كروه آسيب يذير جامعه تمركز نشده است. از آنجا كه مطالعات درباره جَّونى و ميزان رابطه كيفيت زندگى و خودمراقبتى در سالمندان

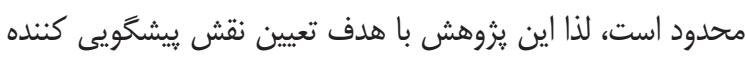
توان خودمراقبتى سالمندان در كيفيت زندگى آنان انجام شد.

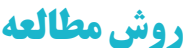

اين يزوهش روش توصيفى - تحليلى به منظور تعيين نقش بيشكويى كننده توان خودمراقبتى در كيفيت زندگى سالمندان ساكن

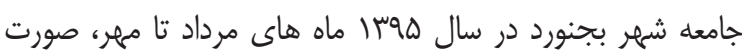
كرفت. شهر مذكور در استان خراسان شمالى واقع در شرق كشور داراى سه منطقه، سى محله و ........ خانوار مى باشد. با توجه به تله

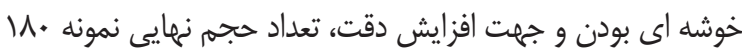
نفر برآورد كَرديد. يرسشنامه هاى مورد نظر در يك يا دو مراجعه به إنه سالمند و با رعايت موازين اخلاقى، توسط سالمند و در صورت نياز

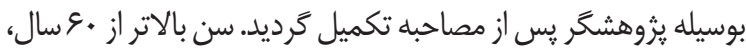
تمايل سالمند و رضايت به شركت در يزوهش، عدم وجود معلوليت

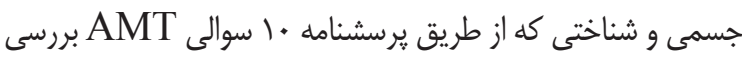
شد و اقامت در شهر بجنورد از معيارهاى ورود مطالعه بودند. نمونه كيرى به روش طبقه اى خوشه اى קُند مرحله اى انجام شد به

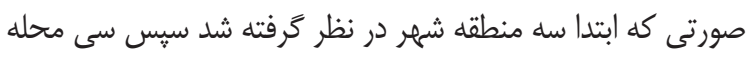

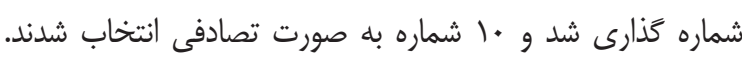
سيس خيابان ها و كوخه ها بطور تصادفى انتخاب و با توجه به لهابه تعداد نمونه براى هر محله \ل يرسشنامه در نظر كرفته شد. با حضور

\section{مقلمهه}

با افزايش قابل توجه سالمندان، بهبود كيفيت زندكى و حفظ

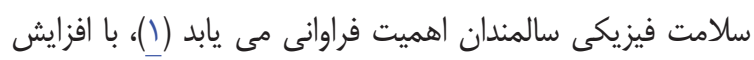

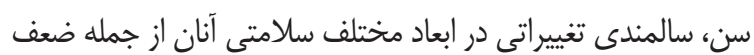
جسمانى، روانى، عقلى و انواع بيمارى ها به وجود خواهد آورد (Г)، لذا با توجه به اين تغييرات، سالمند مستعد آسيب و كاهش كيفيت زندكى

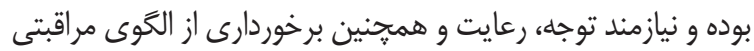
ويرّه مى باشد (ـا) با توجه به اينكه تركيب جمعيتى فعلى كشور را

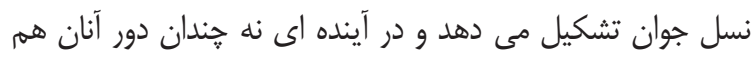

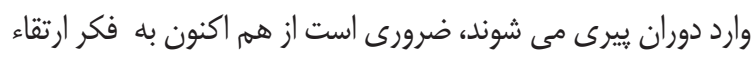
و بهبود ابعاد متعدد مؤثر در كيفيت زندگى آنان باشيهيم (بّ).

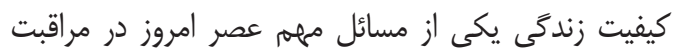
سلامتى است. سازمان بهداشت جهانى تعريف جامعى از كيفيت إز مساريت

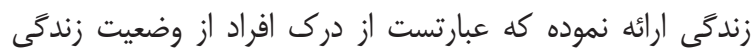
در قالب فرهنگ و ارزش هاى حاكم بر جامعه در راستاى اهداف، استانداردها و علايق افراد (أ). بررسى متغيرهاى مرتبط با كيفيت

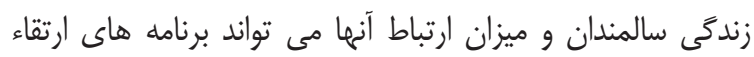

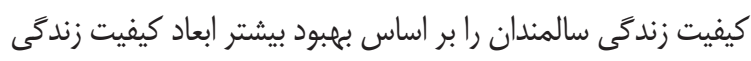

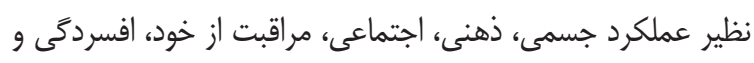

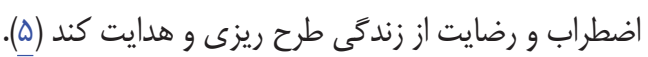

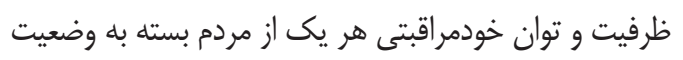

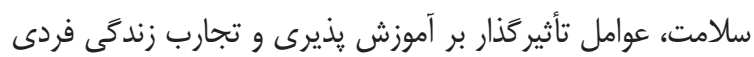
متفاوت است. خودمراقبتى در تمام طيف سلامت و بيمارى معنى ييدا مى كند و مراقبت هاى بهداشتى در طيفى قرار مى گيرند كه دامنه اش از خودمراقبتى ..1 درصد) مثل مسواك زدن منظم روزانه) تا مراقبت حرفه اى ... درصد) مثل جراحى اعصاب (متغير است. بخشى از ناخوشى هاى جزئى، بيماريهاى مزمن و حاد، نيازمند مراقبت هاى يزشكى حرفه اى است و هدف خودمراقبتى، اين است

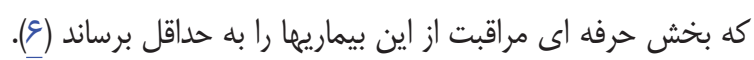

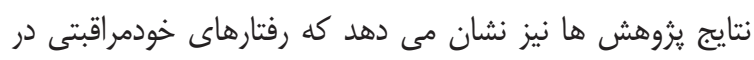

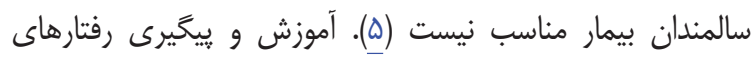
خودمراقبتى بايستى با تمركز بر مشكلات خاص دوران سالمندى، حمايت اجتماعى، ساده سازى رزيم دارويى و غذايى و توجه به ساير بيمارى هاى مزمن انجام كردد (V). در ايران بررسى ها نشان إنان

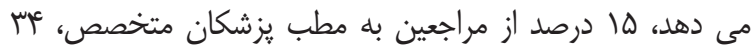

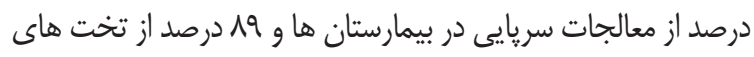


و نمره مساوى و بيشتر از 99 نشان دهنده توان خودمراقبتى بالا

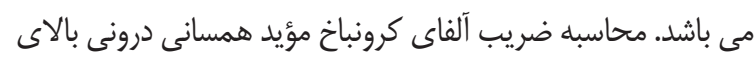

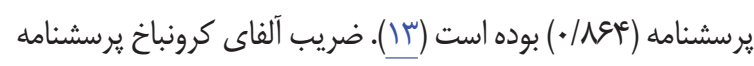

در مطالعه حاضر نيز، بايا بودن آن را مجددا تاييد كرد (•^/•).). جهت رعايت ملاحظات اخلاقى به همه واحدهاى مورد يروهش اطمينان داده شد كه اطلاعات آنها محرمانه باقى مانده و لذا به هر يك از يرسشنامه ها كد داده شد. اهداف يزوهش به طور

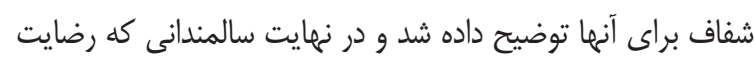
به شركت در مطالعه داشتند مورد بررسى قرار كرفتند. كد اخلاق يزوهش حاضر به-ir-medsab-

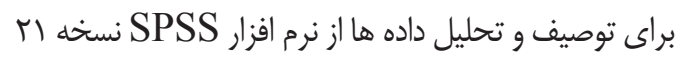

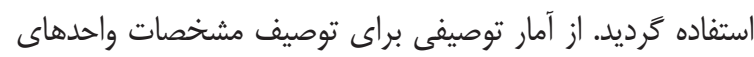

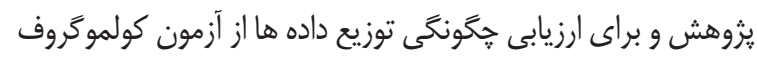
اسميرنوف و براى تعيين تأثير متغيرها از آزمون هاى من ويتنى يو، ضريب همبستىى اسييرمن و تحليل رخرسيون خندعاملى استفاده

\section{كافْته هنا}

كو نفر مرد (qٔدرصد) و MM نفر زن (اله درصد) در كروه نمونه

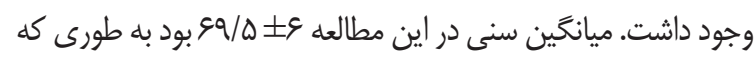

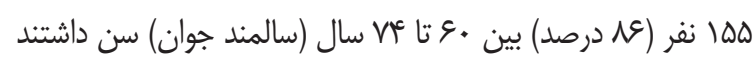
و هr نفر (أl درصد) در رده سنى هV تا •q سال (سالمند سالخورده)

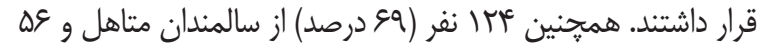
نفر (اس درصد) آنان مجرد و QV درصد زنان، متاهل و آ درصد، مجرد بودند. اين در حالى است كه وضعيت تاهل و تجرد براى مردان

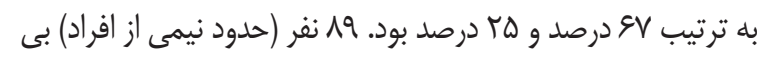

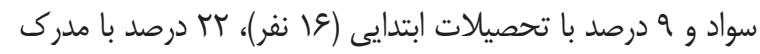

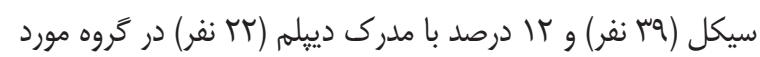

$$
\text { يزوهش حضور داشتند. }
$$

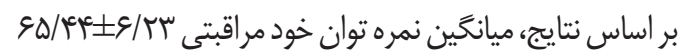

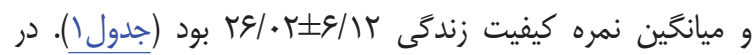
اين يزوهش در بين سالمندان با توان خود مراقبتى بالا، سا نفر

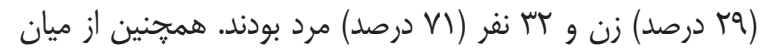

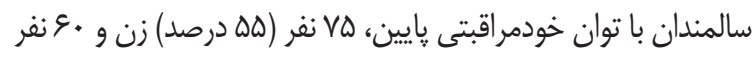

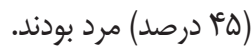

در محله ها و مراجعل به منازل و محل هاى تجمع سالمندان مانند

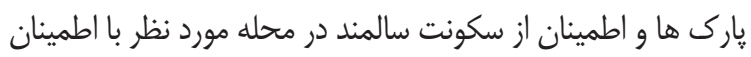

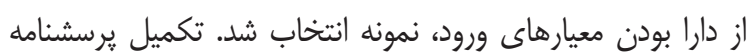
ها در سالمندان با سواد توسط خودشان و در سالمندان بى سواد توسط يُوهشخر انجام شد. در زمان باسخ به يرسشنامه ها توسط سالمند، يزوهشكر در كنار سالمند حضور داشت و به سؤالات ايشان لران ياسخ داد، در صورت خستخى سالمند و يا نياز به ترك محل توسط سالمنل، برسشنامه ها در مراجعه بعدى تكميل شدند و در صورت عدم دسترسى مجدد به ايشان، سالمند از نمونه يزوهش خارج شد.

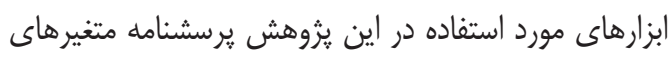

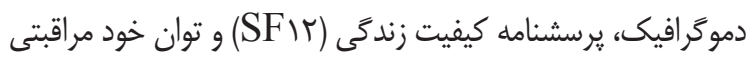

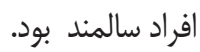
يرسشنامه كيفيت زندگى در سالمندان: فرم كوتاه برسشنامه كيفيت زندَّى در سالمندان (SFIT) داراى rا سؤال مى باشد كه غالبا به صورت مصاحبه توسط يُوهشكَر استفاده مى شود. شيوه نمره كذارى اين برسشنامه در درجه بندى مختلف صورت مى گيرد. در

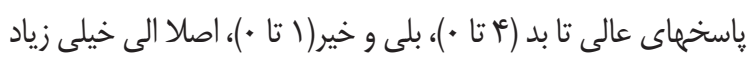

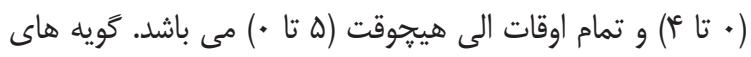

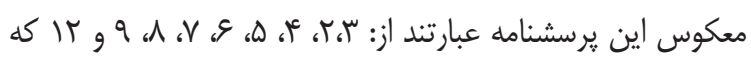

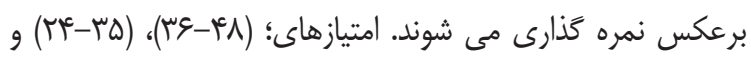

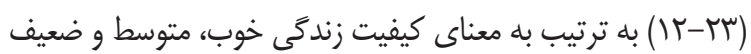
مى باشد. روايى اين يرسشنامه در يزوهش حبيبى سولا، نيكيور، صحبت زاده و همكاران (عمبا)، از طريق اعتبار محتوى و پايايى

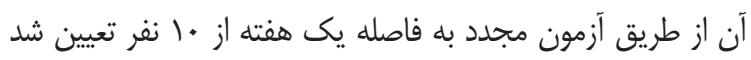
(r=•/9) مطالعه ضريب همبستخى درونى يرسشنامه محاسبه شد كه آلفاى كرونباخ و / • بدست آمد كه مطلوب ارزيابى شد.

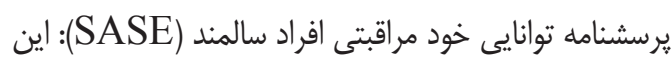

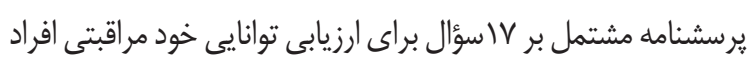
سالمند است. بر اساس عامل خود مراقتى اورم شامل فعاليت خود مراقبتى و توان خود مراقبتى طراحى شده است. ياسخ هر سؤال بر اساس مقياس ليكرت است كه امتيازات بين ا تا ه تقسيه بندى شده است. پاسخ به سؤالات به صورت كاملا موافقه، موافقه، نظرى ندارم، مخالفم و كاملا مخالفم مى باشد، با آيتم بار منفى دارند كه شامل

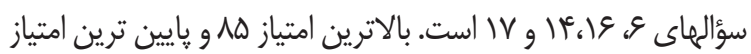
VI امى باشد. نمره كمتر از و9 نشان دهنده توان خود مراقبتى يايين 
جدول (: توزيع فراوانى نمرات كيفيت زندگى و توان خودمراقبتى در سالمندان مورد مطالعه

\begin{tabular}{|c|c|c|c|c|c|}
\hline بيشترين نمره & كمترين نمره & انحراف معيار & ميانكين & تعداد & متغير \\
\hline ᄉ) & D. & אT/R & $9 D / \varphi^{c} T^{c}$ & $M$. & توان خودمراقبتى \\
\hline rq & Ir & S/IT & G/IT & $M$. & كيفيت زندگى \\
\hline
\end{tabular}

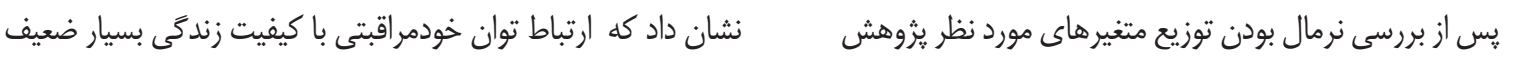

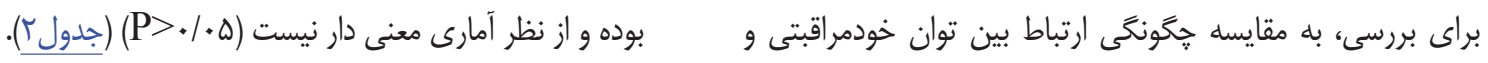

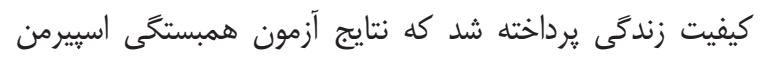
جدول r: مقايسه همبستكى توان خودمراقبتى با كيفيت زندَّى در سالمندان مورد مطالعه

\begin{tabular}{|c|c|c|}
\hline $\mathrm{P}$ - value & ضر يب همبستكى (r) & متغيرها \\
\hline نوع آزمون: اسِيرمن & מאוא. & توان خود مراقبتى \\
\hline
\end{tabular}

تاثير كذار بر روى نمره كيفيت زندگى سالمندان، با توجه به

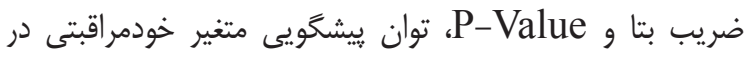

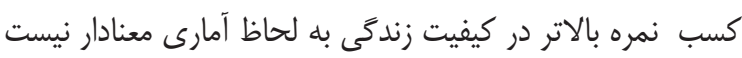

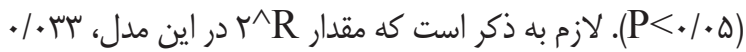
است يعنى تنها سه درصد از يراكندگى مشاهده شده در اين مدل توسط متغيرهاى مورد مطالعه، تبيين مى شود (جدول بّ).
نتايج آزمون همبستخى اسيرمن در (جدول ب) نشان مى دهد

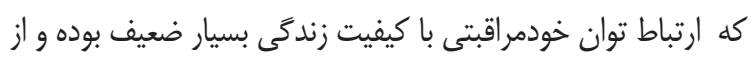

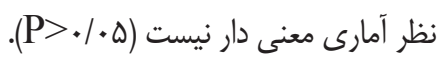

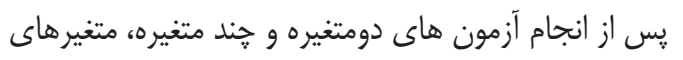

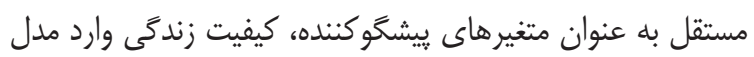
ركرسيونى شدند كه مشخص شد با در نظر گرفتن تمام متغيرهاى

\begin{tabular}{|c|c|c|c|c|}
\hline $\mathrm{P}$-value & آماره آزمون (t) & (ß) ضريب بتا & (ضريب ركرسيون) B & متغير \\
\hline .1 .94 & I/AVA & .1119 &.$/ 11 \mathrm{~V}$ & توان خودمراقبتى \\
\hline.$/ 941$ & .1 .99 & $\cdot 1+1$ & $\cdot 1 \cdot+1$ & سن \\
\hline ./TIV & 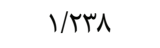 & $.11 \cdot 1$ & •/ HAD & سطح تحصيلات \\
\hline$\cdot / 9 V \Lambda$ &.$- / 419$ & Trt. & $-\cdot /$ /qV & جنسيت \\
\hline . & $. / 4 \mid$. & (. & . $/ 4 F \Delta$ & تاهل \\
\hline
\end{tabular}

و تفاوت در ميانگين سنى نمونه ها، در يايين بودن نتيجه تاثير داشته

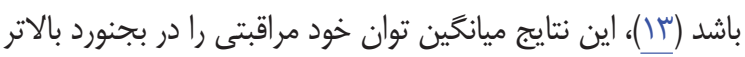

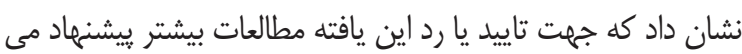

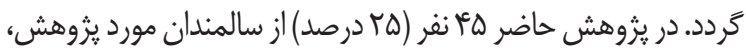
توان خودمراقبتى بالا و هـا نفر (VD درصد) توان خود مراقبتى یإيين

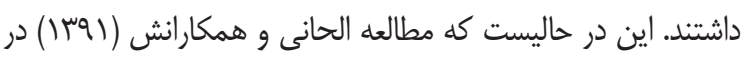
كرج و شهريار در بررسى ميزان يِيروى از رفتارهاى خودمراقبتى نشان

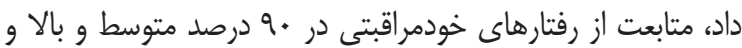
•ا درصد يايين بود (ج) لذا در مقايسه با مطالعه حاضر نتايج همسو نبوده بطورى كه در سالمندان شهر بجنورد توان خودمراقبتى پايين بـاين

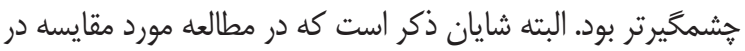
كرج و شهريار، بيمارانى وارد مطالعه شدند كه به نارسايى قلبى مبتلا بودند و اين افراد احتمال دارد در خصوص خود مراقبتى آموزش ديداني باشند كه مى تواند در نتايج مطالعه تاثير گذار باشد. همجنين ميانگِين

\section{ب0}

نتايج اين يزوهش نشان داد در شهر بجنورد، مردان سالمند از ميزان توان خود مراقبتى بالاترى نسبت به زنان سالمند برخوردار بودند. در بررسى اين يافته در تاييد يافته قبلى كمك كننده بود و ور برد

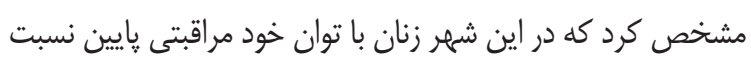
به مردان، درصد بيشترى را به خود اختصاص مى دهند. همجنين يافته ها در مطالعه حاضر نشان مى دهد كه بطور كلى در بين زنان،

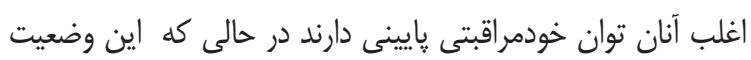

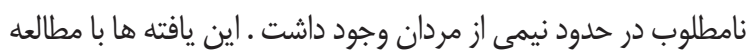
خوش تراش و همكاران (919-1) مراقبتى و عوامل مرتبط با آن در شهر رشت همخوانى نداشت و در

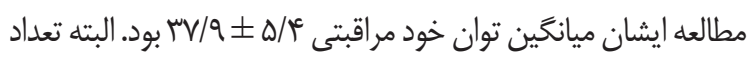
نمونه در مطالعه خوش تراش سب نفر بود، كه شايد تعداد نمونه كمتر 
هيج يك از عوامل جنس، تحصيلات، تأهل و سن نيز توان ييشكويى

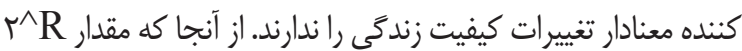
در اين مدل، سب./• است اين به معنى آن است كه تنها سه درصد از بر اكندَّى مشاهده شده در اين مدل توسط متغير هاى مورد مطالعه،

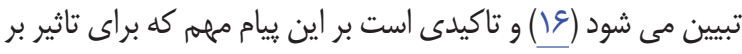

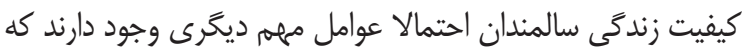
نقش بارزترى در ييش گويى اين متغير دارند و مى بايست با انجام مطالعاتى دقيق ترى آنها را شناسايى نمود.

محدوديت هاى يزوهش: خستكى سالمند حين تكميل يرسشناهه ها كه با تكميل يرسشنامه ها در خند مر اجعه رفع كَرديد. قابل ذكر است كه وضعيت جسمى و روحى فرد سالمند در هنعام

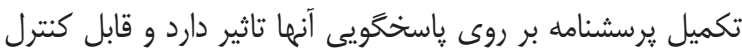

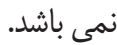

\section{تُتيجه تَيرى نهايى}

در اين جامعه يزوهشى، بين كيفيت زندَّى و توان خودمراقبتى رابطه معنادارى وجود نداشت و توان خودمراقبتى برانى نمى تواند نقش ييشكَوكننده اى در تغييرات وضعيت كيفيت زندَّى در سالمندان داشته باشد. همجنين با توجه به توان خود مراقبتى پإيين اكثر سالمندان شهر بجنورد و بخصوص زنان سالمند اين شهر، توصيه مى شود عوامل موثر بر توان خود مراقبتى بررسى و برنامه ريزى و اقدامات لازم در خصوص بهبود وضعيت توان خودمراقبتى از سوى

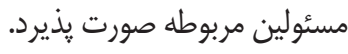

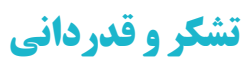

از همه مسئولين محترم دانشخاه علوم بزشكى سبزوار كه

امكان يزوهش را براى محقق فراهم نمودند و بويزه سالمندان

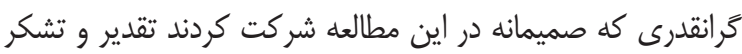

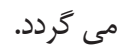

\section{References}

1. Kun L. Telehealth and the global health network in the 21st century From homecare to public.2007; 211-12.

2. AHmadi F, Salar A, Faghih Zadeh S. Quality of life of elderly people in Zahedan. Journal of Life. 2004; 10 (22): 61-7.(Persian).

3. Glanz KaR, BK. Theory at a Glanz :A Guide for Health Promotion Practice. Dept of Health and Human Services public دوره r شماره F بهار rqu
سنى گروه نمونه نيز كمتر بوده است. با توجه به پايين بودن درصد توان خودمراقبتى بالا در سالمندان ساكن جامعه شهر بجنورد، توصيه برديه مى شود عوامل موثر بر توان خود مراقبتى بررسى و تلاش هاى بيشترى براى برنامه ريزى و انجام اقدامات لازم براى بهبود وضعيت

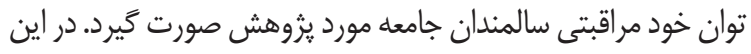
راستا آموزش به بيماران در مورد اهميت و نحوه انجام رفتارهاى خود مراقبتى در ارتقاء اين رفتارها و در نتيجه كاهش ميزان مرك و مير دير و هزينه هاى بسترى شدن بسيار موثر مى باشد كه يرستاران نقش مهمى را در آموزش اين رفتارها بر عهده دارند. بر اساس نتايج اين يزوهش، در بررسى رابطه بين كيفيت

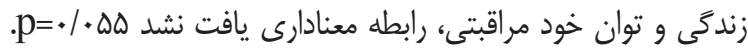
اين يافته با مطالعه سالار و همكاران در زاهدان كه نشان داد مشاوره

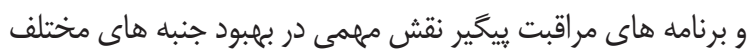
كيفيت زندگى سالمندان ايفا مى كند و خودمراقبتى كيفيت زندگى لنى

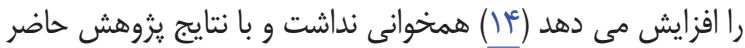
مغايرت دارد. البته تاييد يا رد اين موضوع نيازمند انجام مطالعات بيشتر با مقياس ها و شرايط مشابه دارد. يافته هاى جانبى بدست أمده به منظور تعيين ارتباط ساير متغيرهاى دموگرافيك از جمله سن، جنسيت، تحصيلات و تأهل با كيفيت زندگىى، نتايج نشان داد كه ارتباط متغيرهاى جنس و تحصيلات معنادار شده است

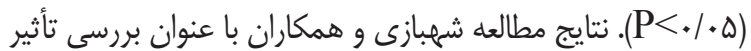
برنامه آموزشى خودمراقبتى بر كيفيت زندگى ارتباط كيفيت زندگى با بان

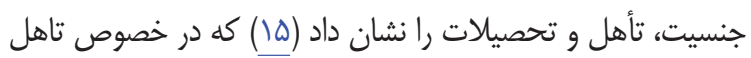
با اين مطالعه همسو نبود. بنابر نتايج ارزشمند جدول ركرسيون در مطالعه حاضر، با در نظر كَرفتن تمام متغيرهاى تاثيركذار بر روى نمره كيفيت زندكَى

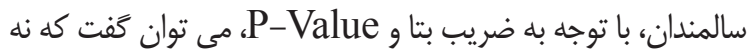
تنها توان ييشكَويى كننده متغير خودمراقبتى در كسب نمره بالاتر

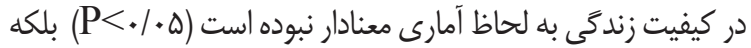

Health Service, National institues of Health. 1997;4-5.

4. Hesamzade A, Seyed Madah B, Mohamadi SHahbalaghi F, Falahi KHoshknab M, Rahgozar M. Comparing the quality of life of seniors living in households with elderly residents of the Nursing home residents Tehran's public and private. Iranian Journal of Ageing. 2009; 4 (14): 66-74.(Persian).

5. Educational package and Self-care 
information. 2014; 1 (1):1-8.

6. Alhani f, Zeighami mohamadi S, SHakoor M, Farmani P, Fahidi F, Mohseni B. Adherence of self-care behaviors in patients with systolic heart failure hospitalization in social security Alborz hospital of Karaj and Shahriar. Journal Faculty of Allied Health Sciences. 3 (11) 2013; 42-9.(Persian).

7. Moshtaghi Neda. The National Plan for the Development of the Health System, Welfare and Dignity of the Elderly of Iran based on the Islamic Model of Iran Progress of the Ministry Health \& Medical Education. 1391.(Persian).

8. Landefeld Se. A randomized trial of care in a hospital medical unit especially designed to improve the functional outcomes of acutely ill older patients. N Engl J Med. 1995; 332:1338-44.

9. Moaddab F, Ghanbari A, Salari A, Kazemnejad E, Sadaghi Sabet M, Pariad E. Study Status Of Self-Care Behaviors And Gender Differences In Patients With Heart Failure. Journal Faculty of Allied Health Sciences, Tehran University of Medical Sciences (Health Payavard). 2014; 8 (3):22034 (Persian).

10. Ghotbi T, Maddah S, Dalvandi A, Arsalani N, Farzi M. The effect of education of self care behaviors based on family-centered empowerment model in type II diabetes. Journal of School of Nursing and Midwifery, Martyr Beheshti University of Medical Sciences and Health Services. 2013; 23 (83): 43-50.(Persian).

11. Habibi Sola A, Nikpoor S, Sohbatzadeh R, Haghani H. Quality Of Life in elderly people of west of Tehran. J Nursing Research. 2007; 2 (6-7): 29-35.(Persian).

12. Hemmati Maslakpak M, Hashemlo L. Design and Psychometric Properties of a Self-Care Questionnaire for the Elderly.
Iranian Journal of Ageing. 2015; 10 (3). (Persian).

13. Khoshtarash M, Ghanbari A, Salehzadeh A, Rahmatpour P. Self-care behaviors and related factors in patients with heart failure. Holist Nurs Midwifery. 2013; 23 (1):9-22. (Persian).

14. Salar A, Ahmadi F, Faghih Zadeh S. Study of effectiveness of continuous care consultation on the quality of life of elderly clients. Tabib shargh. 2003; 4 (5): 261-7.(Persian).

15. SHahbazi S, heidari M. The effect of curriculum Self Care On Quality of life. Iran Journal of Nursing. 2012; 25 (75): 1-8. (Persian).

16. Sharifi HP. Principles of psychometric and psychological testing Tehran. Roshd publisher. 14th Edition. 2011; 211. 